\title{
Dampak Gempa Bumi Terhadap Kelayakan Usaha Sapi Potong Model Integrasi Padi-Ternak di DIY (Studi Kasus di Kecamatan Jetis, Kabupaten Bantul)
}

\author{
Sugeng Widodo, N. Hidayat dan Suharsono \\ Balai Pengkajian Teknologi Pertanian Yogyakarta, Yogyakarta
}

\section{INTISARI}

Selain korban jiwa, rumah dan infrastruktur lainnya, gempa bumi yang terjadi di DIY dan sebagian wilayah Jawa Tengah pada 27 Mei 2006 memberikan dampak negatif terhadap sektor pertanian khususnya sub sektor peternakan. Hal ini secara tidak langsung akan berpengaruh terhadap produktivitas dan kualitas ternak yang dipeliharanya. Hal ini karena selama 2 sampai 3 minggu pasca gempa petani masih sibuk dengan bersih-bersih rumah serta urusan logistik. Kondisi ini juga berpengaruh terhadap pengelolaan sapi potong model kelompok yang sudah berjalan dengan baik menjadi terlantar. Lokasi penelitian merupakan korban berat karena gempa yaitu Kecamatan Jetis Kabupaten Bantul. Di lokasi inilah telah diterapkan introduksi teknologi Padi-Ternak dengan menggunakan ternak potong jenis Siemental dan Limousin. Metodologi pendekatan adalah mengestimasi kelayakan finansial saat fase Pra pemulihan (1 sampai 2 bulan); fase Pemulihan (3 sampai 6 Bulan) dan fase Rekonstruksi (1 sampai 2 tahun) pasca gempa berdasarkan pada data dan hasil analisis sebelum gempa terjadi. Metode penelitian secara Quick Assessment (QA) di wilayah gempa dan dilakukan wawancara terbuka secara partisipatif pada 10 responden dari 30 anggota kelompok ternak yang mengintroduksikan teknologi SIPT. Berdasarkan hasil analisis kelayakan usaha sebelum gempa, usaha ternak sapi potong layak dengan indikator nilai $\mathrm{B} / \mathrm{C}>1,0$, Net Present Value (NPV) positif dan Internal Rate of Return (IRR) aktual $>$ IRR estimate. Hasil penelitian menunjukkan bahwa : (1) pada fase Pra Pemulihan secara finansial usaha ternak sapi potong mengalami kerugian dengan indikator nilai $\mathrm{Net} \mathrm{B} / \mathrm{C}<1,0$; IRR $<\mathrm{IRR}$ estimate (12\%) dan nilai NPV negatif, (2) pada fase Pemulihan dan fase Rekonstruksi usaha ternak sapi potong sudah mulai pulih dan memberikan keuntungan dengan indikator nilai Net B/C $>1,0 ;$ NPV positif dan IRR aktual $>$ IRR estimate, namun pada (3) fase Rekonstruksi usaha sapi potong ini mengalami keuntungan dengan indikator nilai Net $\mathrm{B} / \mathrm{C}>1,0$; NPV positif dan IRR aktual $>$ IRR estimate.

Kata kunci : sapi potong, integrasi padi-ternak, kelayakan, pasca gempa

\section{PENDAHULUAN}

Pengembangan usaha ternak sapi dihadapkan pada persaingan terbuka dan akan terjadi persaingan kompetitif yang sangat tinggi di pasar domestik. Harga dan kualitas barang semakin bersaing, sedangkan faktor pemerintah tidak bisa lagi terlalu intervensi langsung terhadap sektor ini. Oleh sebab itu, terobosan dan masukan teknologi usahatani peternakan secara umum dan khususnya pada teknologi pengembangan sapi sangat dibutuhkan untuk peningkatan produktivitas sapi. Konsumsi daging terus mengalami kenaikan selama dekade 10 tahun terakhir ini. dari 3.81.000 ton pada tahun 1995 menjadi 667.091 (Badan Pusat Statistik, 2005) sedangkan produksi daging sapi di DIY meningkat selama 4 tahun terakhir (2001 sampai 2005) dari $4.788,187$ ton menjadi $6.848,448$ ton dengan kenaikan rerata $9 \%$. Kenaikan daging sapi ini selaras dengan kenaikan konsumsi daging sapi di DIY 
rerata 12 sampai $15 \%$ per tahun (Dinas Pertanian DIY, 2006).

Terbatasnya luas lahan garapan di propinsi DIY dan diiringi sulitnya memperoleh pakan ternak pada musimmusim tertentu, telah mendorong masyarakat mengembangkan usaha yang bertumpu pada pemanfaatan sumberdaya secara efisien, antara lain pemanfaatan limbah pertanian untuk pakan sapi, dimana jerami menjadi alternatif pengganti sebagian rumput. Salah satu usaha yang dapat dikembangkan adalah teknologi dengan pola Sistem Integrasi Padi-Ternak (SIPT) yang mempertimbangkan

sustainable, ramah lingkungan (environmentally tolerable), secara sosial diterima masyarakat (socially acceptable), secara ekonomi layak (economically feasible) dan diterima secara politis (politically desirable) (Diwyanto et al., 2000).

Kejadian gempa bumi di Provinsi DIY dan Klaten sangat mengejutkan masyarakat. Menurut BMG (2006) gempa bumi tektonik ini berkekuatan 5,9 Skala Richter mengakibatkan korban jiwa, benda dan segala aspek kehidupan masyarakat. Dampak secara langsung akibat gempa bumi adalah kehancuran total rumah sekitar 50$70 \%$ bahkan ada yang lebih dari $90 \%$ rubuh rata tanah, serta infrastruktur lainnya (jalan, irigasi, sarana ibadah, kantor, sekolah dll), dan secara tidak langsung adalah trauma yang berkepanjangan, terutama mempengaruhi produktivitas dan kualitas ternak sapi. Hal ini berkaitan dengan kesulitan petani dalam pemeliharaannnya dimana fokus sekarang masih pada penyelamatan jiwa, maka ternak akan terlantar karena kesulitan pakan. Dalam kaitannya dengan kerusakan sarana dan prasarana sektor ini adalah : sebagian besar juga terjadi kerusakan pada bangunan kandang sapi baik secara permanen maupun semi permanen. Hal ini menyebabkan kesulitan bagi peternak dalam pemeliharaan secara intensif dan akibatnya akan berpengaruh terhadap kualitas dan kuantitas sapi potong tersebut. Kerusakan akibat gempa pada sub sektor peternakan ditunjukaan dengan robohnya bangunan kandang. Sejumlah 255 unit kandang pada lokasi gempa ditemukan 34 unit kandang yang roboh. Tingkat kerugian sub sektor peternakan akibat gempa diperkirakan Rp 371.500.000 (Dinas Pertanian DIY, 2006).

\section{MATERI DAN METODE}

Penelitian dilakukan di Desa Canden, Kecamatan Jetis, Kabupaten Bantul. Pola SIPT terdapat tiga komponen teknologi utama yaitu : (a) teknologi budidaya ternak; (b) teknologi budidaya padi; dan (c) teknologi pengolahan jerami dan kompos. Teknologi budidaya tanaman dikaitkan dengan Pengolahan Tanaman dan Sumberdaya Terpadu Padi Sawah Irigasi. Pendekatan analisis meliputi kelayakan usaha ternak sapi potong sebelum gempa, mengestimasi kelayakan finansial pasca gempa pada saat fase Pra pemulihan; fase Pemulihan dan fase Rekonstruksi. Metode penelitian pasca gempa dilakukan secara Quick Assessment (QA) dengan wawancara terbuka secara partisipatif pada 10 responden dari 30 anggota kelompok ternak yang mengintroduksikan teknologi SIPT.

\section{Analisis Data}

Analisis Investasi jangka panjang meliputi : NPV dan IRR.. (Before dan After) Gempa bumi. (Gittinger, 1986).

a. NPV :

$$
N P V=\sum_{t=i}^{t=n} \frac{\left(B_{t}-C_{t}\right)}{(1+i)^{t}}
$$

Kriteria NPV yaitu :

NPV > 0, layak;

$\mathrm{NPV}<0$, tidak layak;

$\mathrm{NPV}=0$, impas

b. Net Benefit Cost Ratio (Net B/C Ratio) :

$$
B / C=\left\{\sum_{i=1}^{t=n} B t /(1+i)^{t}\right\} /\left\{\sum_{i=1}^{t=n} C t /(1+i)^{t}\right\}
$$


$\underline{\text { Kriteria Net B/C Ratio yaitu : }}$

Net B/C Ratio $>1$, menguntungkan

Net $B / C$ Ratio $<1$, tidak menguntungkan

c. IRR yaitu :

$$
\operatorname{IRR}=\sum_{t=1}^{t=n} \frac{\left(B_{t}-C_{t}\right)}{(1+i)^{t}}=0
$$

Keterangan :

$\mathrm{B}=$ Manfaat penerimaan tiap tahun

$\mathrm{C}=$ Manfaat biaya yang dikeluarkan tiap tahun

$\mathrm{t}=$ Tahun kegiatan usaha $(\mathrm{t}=1,2, . . \mathrm{n})$

$\mathrm{i}=$ Tingkat discount yang berlaku

Kriteria IRR yaitu :

IRR > Social Discount Rate berarti usaha layak

IRR $<$ Social Discount Rate berarti usaha tidak layak

\section{HASIL DAN PEMBAHASAN}

\section{Potensi Sumberdaya Manusia}

Desa Canden memiliki potensi sumberdaya alam dan sumber daya manusia yang cukup beragam. Total penduduk Desa Canden adalah sebanyak 10.075 jiwa yang terdiri atas 4.803 jiwa $(47,68 \%)$ laki-laki dan 5.272 jiwa $(52,32 \%)$ perempuan. Ditinjau dari aspek pendidikan penduduk desa Canden sangat bervariasi mulai belum sekolah $(18,84 \%)$, tidak tamat SD $(13,47 \%)$, SD $(47,46 \%)$, SLTP $(11,21 \%), \quad$ SLTA (7,31\%), Akademi $(0,86 \%)$ dan Sarjana $(0,84 \%)$. Seluruh populasi penduduk ada $62 \%$ bekerja di sektor pertanian dan $38 \%$ lainnya di luar sektor pertanian (Monografi Desa Canden, 2003).

\section{Analisis Finansial}

Dilakukan pendekatan dengan arus tunai berdiskonto pada tingkat bunga $12 \% /$ tahun atau discount factor $1 \%$ per bulan sesuai dengan suku bunga komersial. Output yang dihasilkan adalah anak sapi siap jual dengan bobot badan dan umur sesuai harga pasar; kompos hasil pengolahan limbah sapi dikemas dalam ukuran plastik ukuran $5 \mathrm{~kg}$. Pada kasus penelitian ini untuk sapi afkir (sesuai umur ekonomis) tidak diperhitungkan. Investasi awal adalah: kandang kelompok, tempat prosesing limbah/kompos, tempat prosesing jerami, peralatan kerja/habis pakai dan pembelian sapi bakalan/siap bunting.

Biaya tetap adalah biaya yang dikeluarkan setiap tahun terdiri dari sewa lahan kandang, pajak dan peralatan kerja. Biaya yang dikeluarkan untuk operasional yang terdiri dari probiotik jerami, konsentrat, probiotik kompos, serbuk gergaji, BBM/listrik, obat-obatan, vaksin, IB, transportasi untuk jerami dan sapi, pupuk urea, pupuk SP-36 dan tenaga kerja (luar dan sendiri). Hasil Analisis finansial usaha ternak sapi potong model SIPT sebelum gempa disajikan pada Tabel 1 .

Berdasarkan hasil analisis sebelum gempa selama 5 (lima) tahun investasi, usaha sapi potong model SIPT layak dengan indikator nilai Net $\mathrm{BC}>1,0$ yaitu 1,45 ; kemudian nilai IRR aktual 14\% $>$ IRR estimate (12\%); juga dengan indikator nilai NPV positif sebesar Rp. 9.257.190. Berdasarkan hasil analisis pasca gempa pada pra pemulihan, petani hanya berkonsentrasi pada perbaikan rumah maka pemeliharaan ternak agak terlantar, hal ini menyebabkan bobot ternak turun drastic sebesar 15\%. Demikian pula harga ternak dan kompos jatuh sampai dengan $50 \%$, namun disisi lain biaya input naik sekitar 40\%. Hal ini menyebabkan usaha ternak merugi dengan indicator nilai IRR actual $10,8 \%<$ IRR estimate (12\%), demikian pula nilai NPV negatif sebesar Rp 5.751.000,- (Tabel 2).

Pada kondisi fase pemulihan dan fase rekonstruksi usaha ternak sapi potong dengan model SIPT mulai pulih dengan indikator nilai IRR aktual antara $15 \%$ sampai $16,0 \%$ dengan nilai NPV positif antara Rp 16.505.000,- sampai Rp 22.731.000,-artinya usaha ternak ini layak.

\section{KESIMPULAN}

Dari hasil analisis finansial usaha ternak sapi potong model SIPT selama (5) tahun (2001 sampai 2005) 
(1) Sebelum gempa usaha ternak sapi potong layak dengan indikator nilai rasio $\mathrm{B} / \mathrm{C}>1,0$ yaitu 1,45 ; nilai Internal Rate of Return (IRR) aktual yaitu $14 \%$ atau $>$ IRR estimate (12\%), serta nilai Net Present Value (NPV) positif sebesar Rp 9,257,190,-

(2) Sesudah gempa pada fase pra pemulihan (1-2 bulan) mengalami kerugian dengan indikator nilai IRR aktual $10,8 \%<$ IRR estimate $(12 \%)$, serta nilai NPV negatif sebesar Rp (5,751.000);

(3) Pada fase pemulihan (3-6 bulan) setelah gempa usaha ternak sapi potong layak dengan indikator nilai rasio $\mathrm{B} / \mathrm{C}>1,0$ yaitu 1,51 ; IRR aktual $>$ IRR estimate yaitu serta nilai NPV positif sebesar Rp 16,505.000;

(4) Pada fase rekonstruksi (1 tahun) usaha ini layak dengan indikator nilai rasio $\mathrm{B} / \mathrm{C}>1,0$ yaitu 1,57 ; nilai Internal Rate of Return (IRR) aktual yaitu $16 \%$ atau > IRR estimate (12\%), serta nilai Net Present Value (NPV) positif sebesar Rp 22.731.000.

\section{UCAPAN TERIMA KASIH}

Kepada Sdr. Thomas Kristianto Nugroho (alumnus Pasca Sarjana Magister Manajemen Agribisnis Universitas Gajah Mada), yang sekarang bekerja di Metro TV Jakarta, Tim bencana alam BPTP DIY, dan Tim bencana alam Pusat.

\section{DAFTAR PUSTAKA}

Badan Pusat Statistik D.I.Yogyakarta. 2004. Yogyakarta Dalam Angka 2004-2005. Badan Pusat Statistik Prop. D.I.Yogyakarta.
Badan Pusat Statistik, 2004. Bulletin Statistik Perdagangan Luar Negeri. Import. Edisi Juni 2004. Badan Pusat Statistik. Jakarta.

Badan Pusat Statistik, 1995. Bulletin Statistik Perdagangan Luar Negeri. Import. Edisi Juni 2004. Badan Pusat Statistik. Jakarta.

Dinas Pertanian Propinsi Daerah Istimewa Yogyakarta. Statistik Peternakan. 2000-2004. Dinas Pertanian Prop. D.I.Yogyakarta. 2005.

Dinas Pertanian Propinsi Daerah Istimewa Yogyakarta. Laporan Tahunan Tahun 2006. Dinas Pertanian Propinsi Daerah Istimewa Yogyakarta.

Gittinger, J.P. 1986. Analisis Ekonomi Proyek-Proyek Pertanian. Eds (II). Universitas Indonesia Press, Jakarta.

Diwyanto, K. dan B. Haryanto. 2000. Restrukturisasi Peta Kesesuaian dan Pemberdayaan Sumberdaya Unggulan. Makalah di Sampaikan dalam "Revitalisasi Keterpaduan Unggul Ternak dalam Sistem Usaha Tani", Bogor, 21 Februari-6 Maret 2000.

Monografi Desa Canden. 2003. Kecamatan Jetis. Kabupaten Bantul, Yogyakarta.

Sunandar, 2005. Keunggulan Komparatif Usaha Ternak Sapi Potong di Kabupaten Gunung Kidul. Agros. Universitas Janabadra, Yogyakarta. 8(1): 43-54.

Tim Juknis SIPT. 2001. Petunjuk Teknis SIPT. Petunjuk Teknis Operasional SIPT Propinsi Daerah Istimewa Yogyakarta. Dinas Pertanian. Bagian Proyek Pengembangan Padi Terpadu, Daerah Istimewa Yogyakarta. 
Tabel 1. Analisis Finansial Arus Tunai usaha ternak sapi di Kabupaten Bantul Tahun 2001-2005 Sebelum Gempa Tahun 2005 (x Rp 1.000)

\begin{tabular}{|c|c|c|c|c|c|c|}
\hline & \multirow[b]{2}{*}{ Uraian } & \multicolumn{5}{|c|}{ Tahun } \\
\hline & & 2001 & 2002 & 2003 & 2004 & 2005 \\
\hline & & (T0) & (T1) & (T2) & (T3) & (T4) \\
\hline \multirow[t]{3}{*}{$\mathrm{A}$} & Total Penerimaan & 0 & 90,000 & 241,923 & 241,923 & 241,923 \\
\hline & - Penjualan sapi & 0 & 55,000 & 197,600 & 197,600 & 197,600 \\
\hline & - Penjualan kompos & 0 & 35,000 & 44,323 & 44,323 & 44,323 \\
\hline $\mathrm{B}$ & \multicolumn{6}{|l|}{ Pengeluaran } \\
\hline & 1. Biaya Investasi & 25,100 & & & & \\
\hline & - pembuatan kandang & 40,000 & 0 & 0 & 0 & 0 \\
\hline & - tempat prosesing kompos & 5,000 & 0 & 0 & 0 & 0 \\
\hline & - tempat prosesing jerami & 5,000 & 0 & 0 & 0 & 0 \\
\hline & - Peralatan kerja & 800 & 0 & 0 & 0 & 0 \\
\hline & - Pembelian sapi & 174,300 & 0 & 0 & 0 & 0 \\
\hline & 2. Biaya tetap & 0 & 2,927 & 2,927 & 2,927 & 2,927 \\
\hline & - sewa lahan kandang & 0 & 1,872 & 1,872 & 1,872 & 1,872 \\
\hline & - Pajak & 0 & 54.6 & 54.6 & 54.6 & 54.6 \\
\hline & - Peralatan kerja & 0 & 1,000 & 1,000 & 1,000 & 1,000 \\
\hline & 3. Biaya variabel & 0 & 85,410 & 85,610 & 86,386 & 90,155 \\
\hline & - Probiotik jerami & 0 & 31,200 & 31,200 & 31,200 & 31,200 \\
\hline & - konsentrat & 0 & 19,152 & 19,152 & 19,152 & 19,152 \\
\hline & - probiotik kompos & 0 & 12,312 & 12,312 & 12,312 & 12,312 \\
\hline & - serbuk gergaji & 0 & 2,640 & 2,640 & 2,640 & 2,640 \\
\hline & - Listrik & 0 & 960 & 960 & 960 & 960 \\
\hline & - Obat, vaksin & 0 & 4,530 & 4,530 & 4,530 & 4,530 \\
\hline & - transport & 0 & 1,920 & 1,920 & 2,496 & 3,456 \\
\hline & - urea & 0 & 8,313 & 8,313 & 8,313 & 10,807 \\
\hline & - SP-36 & 0 & 383 & 383 & 383 & 498 \\
\hline & - Tenaga kerja & 0 & 4,000 & 4,200 & 4,400 & 4,600 \\
\hline & Total Pengeluaran & 225,100 & 88,336 & 8,536 & 89,312 & 93,081 \\
\hline $\mathrm{C}$ & Pendapatan bersih & $(225,100)$ & 1,664 & 53,387 & 152,611 & 148,842 \\
\hline $\mathrm{D}$ & df $12 \%$ & 1 & 0.892 & 0.792 & 0.711 & 0.635 \\
\hline $\mathrm{E}$ & Present Value & $(225,100)$ & 1,484 & 121,482 & 108,506 & 94,515 \\
\hline $\mathrm{F}$ & Total PV positif (th1-5) & 324,503 & & & & \\
\hline $\mathrm{G}$ & Total PV negatif (th 0) & $(223,616)$ & & & & \\
\hline $\mathrm{H}$ & Net $\mathrm{B} / \mathrm{C}$ ratio $=\mathrm{F} / \mathrm{G}$ & 1.45 & & & & \\
\hline & Aliran kas tahun ke-0 & $(225,100)$ & & & & \\
\hline & Aliran kas tahun ke-1 & 1,484 & & & & \\
\hline & Aliran kas tahun ke-2 & 121,482 & & & & \\
\hline & Aliran kas tahun ke-3 & 108,506 & & & & \\
\hline & Aliran kas tahun ke-4 & 94,515 & & & & \\
\hline & IRR estimate & $12 \%$ & & & & \\
\hline & IRR aktual & $14 \%$ & & & & \\
\hline & NPV & $9,257,19$ & & & & \\
\hline & Kesimpulan & Layak & & & & \\
\hline
\end{tabular}


Tabel 2. Analisis Finansial Arus Tunai Usaha Ternak Sapi Di Kabupaten Bantul Tahun 2001-2006 (Pra Pemulihan 1-2 bulan) Pasca Gempa (x Rp 1000)

\begin{tabular}{|r|l|r|r|r|r|r|r|}
\hline \multirow{2}{*}{} & \multirow{2}{*}{ Uraian } & \multicolumn{7}{|c|}{ Tahun } & \\
\cline { 3 - 9 } & & 2001 & 2002 & 2003 & 2004 & 2005 & 2006 \\
\hline & & $(\mathrm{T} 0)$ & $(\mathrm{T} 1)$ & $(\mathrm{T} 2)$ & $(\mathrm{T} 3)$ & $(\mathrm{T} 4)$ & \\
\hline A & Total Penerimaan & 0 & 90,000 & 241,923 & 241,923 & 241,923 & 84,673 \\
\hline & - Penjualan sapi & 0 & 55,000 & 197,600 & 197,600 & 197,600 & 69,160 \\
\hline & - Penjualan kompos & 0 & 35,000 & 44,323 & 44,323 & 44,323 & 15,513 \\
\hline
\end{tabular}

B 1 Pengeluaran

\begin{tabular}{|l|l|r|r|r|r|r|r|}
\hline & 1. Biaya Investasi & 225,100 & & & & & \\
\hline 0 & - pembuatankandang & 40,000 & 0 & 0 & & 0 & 0 \\
\hline & - tempat prosesing kompos & 5,000 & 0 & 0 & 0 & 0 \\
\hline
\end{tabular}

\begin{tabular}{|c|c|c|c|c|c|c|c|}
\hline & & & & & & & \\
\hline & - tempat prosesing jerami & 5,000 & 0 & 0 & 0 & 0 & \\
\hline & - Peralatan kerja & 800 & 0 & 0 & 0 & 0 & \\
\hline & - Pembelian sapi & 174,300 & 0 & 0 & 0 & 0 & \\
\hline & 2. Biaya tetap & 0 & 2,927 & 2,927 & 2,927 & 2,927 & 3,927 \\
\hline & - sewa lahan kandang & 0 & 872 & 1,872 & 1,872 & 1,872 & 1,872 \\
\hline & - Pajak & 0 & 54.6 & 54.6 & 54.6 & 54.6 & 54.6 \\
\hline & - Peralatan kerja & 0 & 1,000 & 1,000 & 1,000 & 1,000 & 2,000 \\
\hline & 3. Biaya variabel & 0 & 85,410 & 85,610 & 86,386 & 90,155 & 127,396 \\
\hline & - Probiotik jerami & 0 & 31,200 & 31,200 & 31,200 & 31,200 & 43,680 \\
\hline & - konsentrat & 0 & 19,152 & 19,152 & 19,152 & 19,152 & 26,813 \\
\hline & - probiotik kompos & 0 & 12,312 & 12,312 & 12,312 & 12,312 & 17,237 \\
\hline & - serbuk gergaji & 0 & 2,640 & 2,640 & 2,640 & 2,640 & 3,432 \\
\hline & - Listrik & 0 & 960 & 960 & 960 & 960 & 1,536 \\
\hline & - Obat, vaksin & 0 & 4,530 & 4,530 & 4,530 & 4,530 & 5,889 \\
\hline & - transport & 0 & 1,920 & 1,920 & 2,496 & 3,456 & 4,493 \\
\hline & - urea & 0 & 8,313 & 8,313 & 8,313 & 10,807 & 16,210 \\
\hline & - SP-36 & 0 & 383 & 383 & 383 & 498 & 746 \\
\hline & - Tenaga kerja & 0 & 4,000 & 4,200 & 4,400 & 4,600 & 7,360 \\
\hline & Total Pengeluaran & 225,100 & 88,336 & 88,536 & 89,312 & 93,081 & 131,323 \\
\hline $\mathrm{C}$ & Pendapatan bersih & $(225,100)$ & 1,664 & 153,387 & 152,611 & 148,842 & $(46,650)$ \\
\hline $\mathrm{D}$ & df $12 \%$ & 1 & 0.892 & 0.792 & 0.711 & 0.635 & 0.635 \\
\hline $\mathrm{E}$ & Present Value & $(225,100)$ & 1,484 & 121,482 & 108,506 & 94,515 & $(29,623)$ \\
\hline
\end{tabular}

\begin{tabular}{|r|l|r|}
\hline $\mathrm{F}$ & Total PV positif (th1-5) & 325,987 \\
\hline $\mathrm{G}$ & Total PV negatif (th0) & $(254,723)$ \\
\hline $\mathrm{H}$ & Net B/C ratio = F/G & 1.28 \\
\hline & Aliran kas tahun ke-0 & $(225,100)$ \\
\hline & Aliran kas tahun ke-1 & 1,484 \\
\hline & Aliran kas tahun ke-2 & 121,482 \\
\hline & Aliran kas tahun ke-3 & 108,506 \\
\hline & Aliran kas tahun ke-4 & 94,515 \\
& Aliran Kas tahun ke-5 & $(29,623)$ \\
\hline & IRR estimate & $12 \%$ \\
\hline & IRR aktual & $10,8 \%$ \\
\hline & NPV & $(5,751)$ \\
\hline & Kesimpulan & Tidak layak \\
\hline
\end{tabular}


Tabel 3. Analisis Finansial Arus Tunai Usaha Ternak Sapi Di Kabupaten Bantul (Tahun 2001-2006) Fase Pemulihan 3-6 Bulan Pasca Gempa (x Rp 1.000,-)

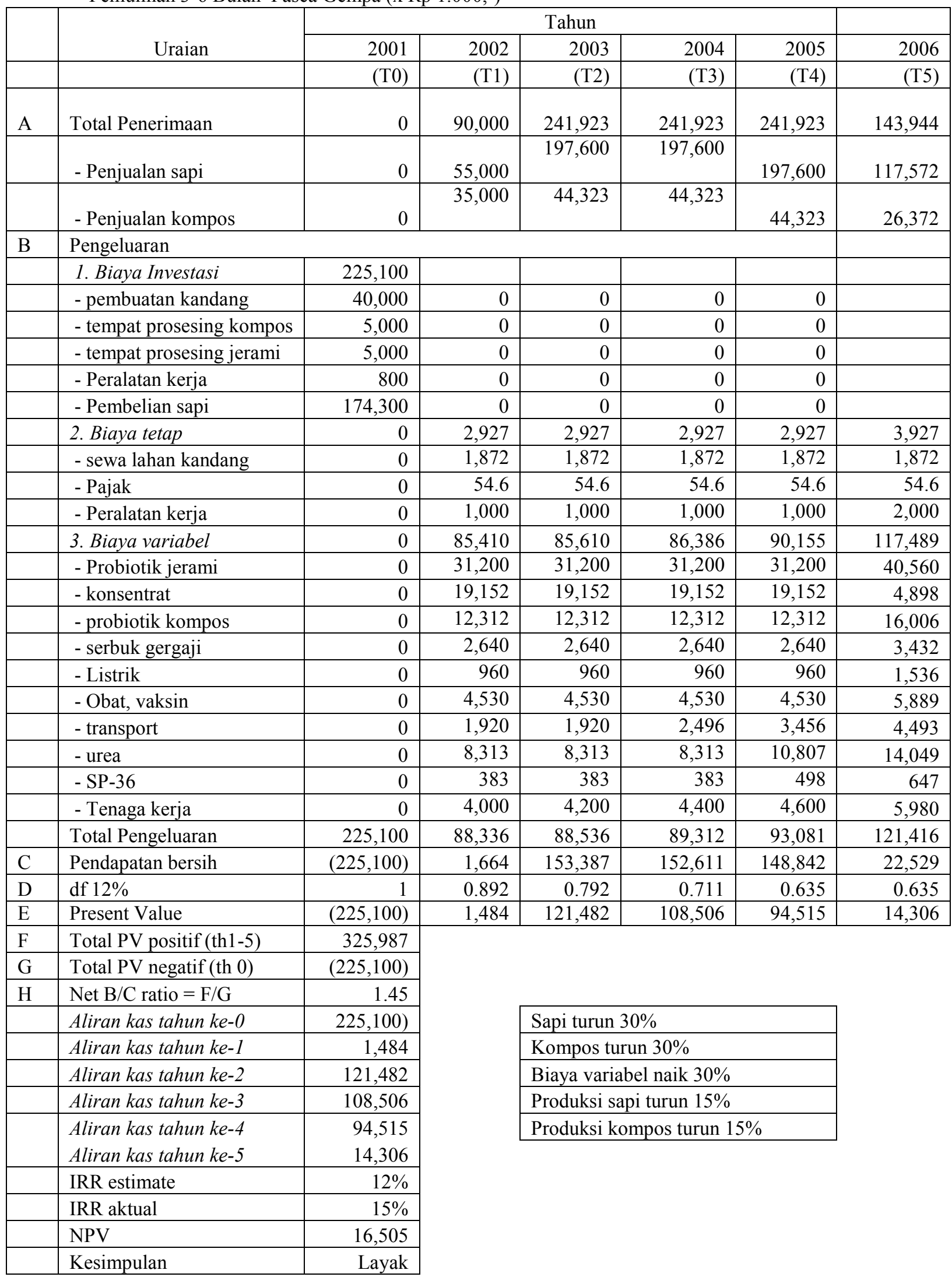


Tabel 4. Analisis Finansial Arus Tunai Usaha Ternak Sapi Di Kabupaten Bantul Tahun 2001-2006 Fase Rekonstruksi (1 tahun) Pasca Gempa (x Rp 1.000,-)

\begin{tabular}{|c|c|c|c|c|c|c|c|}
\hline & \multirow[b]{2}{*}{ Uraian } & \multicolumn{5}{|c|}{ Tahun } & \multirow[b]{2}{*}{2006} \\
\hline & & 2001 & 2002 & 2003 & 2004 & 2005 & \\
\hline & & (T0) & (T1) & (T2) & (T3) & (T4) & \\
\hline \multirow[t]{3}{*}{ A } & Total Penerimaan & 0 & 90,000 & 241,923 & 241,923 & 241,923 & 163,298 \\
\hline & - Penjualan sapi & 0 & 55,000 & 197,600 & 197,600 & 197,600 & 133,380 \\
\hline & - Penjualan kompos & 0 & 35,000 & 44,323 & 44,323 & 44,323 & 29,918 \\
\hline \multirow[t]{23}{*}{$\mathrm{B}$} & Pengeluaran & & & & & & \\
\hline & 1. Biaya Investasi & 225,100 & & & & & \\
\hline & - pembuatan kandang & 40,000 & 0 & 0 & 0 & 0 & \\
\hline & - tempat prosesing kompos & 5,000 & 0 & 0 & 0 & 0 & \\
\hline & - tempat prosesing jerami & 5,000 & 0 & 0 & 0 & 0 & \\
\hline & - Peralatan kerja & 800 & 0 & 0 & 0 & 0 & \\
\hline & - Pembelian sapi & 174,300 & 0 & 0 & 0 & 0 & \\
\hline & 2. Biaya tetap & 0 & 2,927 & 2,927 & 2,927 & 2,927 & 3,927 \\
\hline & - sewa lahan kandang & 0 & 1,872 & 1,872 & 1,872 & 1,872 & 1,872 \\
\hline & - Pajak & 0 & 54.6 & 54.6 & 54.6 & 54.6 & 54.6 \\
\hline & - Peralatan kerja & 0 & 1,000 & 1,000 & 1,000 & 1,000 & 2,000 \\
\hline & 3. Biaya variabel & 0 & 85,410 & 85,610 & 86,386 & 90,155 & 117,489 \\
\hline & - Probiotik jerami & 0 & 31,200 & 31,200 & 31,200 & 31,200 & 40,560 \\
\hline & - konsentrat & 0 & 19,152 & 19,152 & 19,152 & 19,152 & 24,898 \\
\hline & - probiotik kompos & 0 & 12,312 & 12,312 & 12,312 & 12,312 & 16,006 \\
\hline & - serbuk gergaji & 0 & 2,640 & 2,640 & 2,640 & 2,640 & 3,432 \\
\hline & - Listrik & 0 & 960 & 960 & 960 & 960 & 1,536 \\
\hline & - Obat, vaksin & 0 & 4,530 & 4,530 & 4,530 & 4,530 & 5,889 \\
\hline & - transport & 0 & 1,920 & 1,920 & 2,496 & 3,456 & 4,493 \\
\hline & - urea & 0 & 8,313 & 8,313 & 8,313 & 10,807 & 14,049 \\
\hline & - SP-36 & 0 & 383 & 383 & 383 & 498 & 647 \\
\hline & - Tenaga kerja & 0 & 4,000 & 4,200 & 4,400 & 4,600 & 5,980 \\
\hline & Total Pengeluaran & 225,100 & 88,336 & 88,536 & 89,312 & 93,081 & 121,416 \\
\hline $\mathrm{C}$ & Pendapatan bersih & $(225,100)$ & 1,664 & 153,387 & 152,611 & 148,842 & 41,883 \\
\hline $\mathrm{D}$ & df $12 \%$ & 1 & 0.892 & 0.792 & 0.711 & 0.635 & 0.635 \\
\hline $\mathrm{E}$ & Present Value & $(225,100)$ & 1,484 & 121,482 & 108,506 & 94,515 & 26,595 \\
\hline
\end{tabular}

\begin{tabular}{|l|l|r|}
\hline $\mathrm{F}$ & Total PV positif (th1-5) & 325,987 \\
\hline $\mathrm{G}$ & Total PV negatif (th 0) & $(225,100)$ \\
\hline $\mathrm{H}$ & Net B/C ratio = F/G & 1.45 \\
\hline & Aliran kas tahun ke-0 & $(225,100)$ \\
\hline & Aliran kas tahun ke-1 & 1,484 \\
\hline & Aliran kas tahun ke-2 & 121,482 \\
\hline & & \\
& Aliran kas tahun ke-3 & 108,506 \\
\hline & Aliran kas tahun ke-4 & 94,515 \\
& Aliran kas tahun ke-5 & 26,595 \\
\hline & IRR estimate & $12 \%$ \\
\hline & IRR aktual & $16 \%$ \\
\hline & NPV & 22,731 \\
\hline & Kesimpulan & Layak \\
\hline
\end{tabular}

\begin{tabular}{|l|}
\hline Sapi turun $10 \%$ \\
\hline Kompos turun $10 \%$ \\
\hline Biaya variabel naik $30 \%$ \\
\hline $\begin{array}{l}\text { Produksi sapi turun } 25 \% \text { (umur } \\
\text { ekonomis) }\end{array}$ \\
\hline Produksi kompos turun $25 \%$ \\
\hline
\end{tabular}

